\title{
Examining habituation and sensitization across repetitive laboratory stress inductions using the MAST
}

Citation for published version (APA):

Quaedflieg, C. W. E. M., Meyer, T., van Ruitenbeek, P., \& Smeets, T. (2017). Examining habituation and sensitization across repetitive laboratory stress inductions using the MAST. Psychoneuroendocrinology, 77, 175-181. https://doi.org/10.1016/j.psyneuen.2016.12.009

Document status and date:

Published: 01/03/2017

DOI:

10.1016/j.psyneuen.2016.12.009

Document Version:

Publisher's PDF, also known as Version of record

Document license:

Taverne

Please check the document version of this publication:

- A submitted manuscript is the version of the article upon submission and before peer-review. There can be important differences between the submitted version and the official published version of record.

People interested in the research are advised to contact the author for the final version of the publication, or visit the DOI to the publisher's website.

- The final author version and the galley proof are versions of the publication after peer review.

- The final published version features the final layout of the paper including the volume, issue and page numbers.

Link to publication

\footnotetext{
General rights rights.

- You may freely distribute the URL identifying the publication in the public portal. please follow below link for the End User Agreement:

www.umlib.nl/taverne-license

Take down policy

If you believe that this document breaches copyright please contact us at:

repository@maastrichtuniversity.nl

providing details and we will investigate your claim.
}

Copyright and moral rights for the publications made accessible in the public portal are retained by the authors and/or other copyright owners and it is a condition of accessing publications that users recognise and abide by the legal requirements associated with these

- Users may download and print one copy of any publication from the public portal for the purpose of private study or research.

- You may not further distribute the material or use it for any profit-making activity or commercial gain

If the publication is distributed under the terms of Article $25 \mathrm{fa}$ of the Dutch Copyright Act, indicated by the "Taverne" license above, 


\title{
Examining habituation and sensitization across repetitive laboratory stress inductions using the MAST
}

\author{
C.W.E.M. Quaedflieg ${ }^{a, b, *}$, T. Meyer ${ }^{\text {b,c }}$, P. van Ruitenbeek ${ }^{b}$, T. Smeets $^{\text {b }}$ \\ a Department of Cognitive Psychology, Institute for Psychology, University of Hamburg, Germany \\ ${ }^{\mathrm{b}}$ Faculty of Psychology and Neuroscience, Maastricht University, The Netherlands \\ c Behavioral Science Institute, Radboud University Nijmegen, The Netherlands
}

\section{A R T I C L E I N F O}

\section{Article history:}

Received 19 September 2016

Received in revised form

18 November 2016

Accepted 16 December 2016

\section{Keywords:}

Repeated stress protocols

Maastricht Acute Stress Test (MAST)

Stress habituation

Stress sensitization

Cortisol

\begin{abstract}
A B S T R A C T
Reliably eliciting acute stress repeatedly over time is of indispensable value for research into stress vulnerability and for developing interventions aimed at increasing stress resiliency. Here, we evaluated whether the Maastricht Acute Stress Test (MAST), a potent stress protocol that combines physical and psychosocial stress components, can be used to reliably elicit subjective and neuroendocrine stress responses multiple times. Sixty healthy undergraduate participants were exposed to the MAST on three occasions, with intervals of three-weeks and one-month in between sessions. Results showed no significant signs of habituation or sensitization to the MAST in terms of subjective or physiological (salivary alpha-amylase and cortisol) stress reactivity. Fifty-nine percent of the sample displayed a significant physiological stress response (i.e., cortisol) to two MAST exposures and 57\% to every MAST exposure. This study demonstrates that the MAST can be used to repeatedly induce significant stress responses.
\end{abstract}

(C) 2016 Elsevier Ltd. All rights reserved.

\section{Introduction}

The neuroendocrine response to stress comprises two physiological systems. Initially, catecholamines are released via the autonomic nervous system (ANS), serving to initiate a "fight-orflight" response. This is followed by the cortisol response through the slower hypothalamic-pituitary-adrenal (HPA) axis that comes on-line during the selection of a proper behavioral response in the context of the stressor (de Kloet et al., 2005; Ulrich-Lai and Herman, 2009). Dysfunctional HPA axis regulation has been implicated in a variety of psychiatric disorders, as well as in the susceptibility to develop psychopathology after stressful experiences (de Kloet et al., 2005; Wingenfeld and Wolf, 2015). Therefore, it is of critical importance to investigate individual differences in stress responsivity, as well as interventions that alter stress responsivity over time. For this purpose, methods that can effectively and robustly elicit neuroendocrine stress responses without significant habituation or sensitization are indispensable.

Prior research indicates that it is challenging to elicit stress repeatedly in a laboratory due to stress response habituation, as

\footnotetext{
* Corresponding author at: Conny Quaedflieg, Faculty of Psychology and Neuroscience, Maastricht University, P.O. Box 616, 6200 MD Maastricht, The Netherlands. E-mail address: conny.quaedflieg@maastrichtuniversity.nl (C.W.E.M. Quaedflieg).
}

reflected in the attenuation of the physiological stress response. ${ }^{1}$ For instance, evidence for habituation effects have been reported for several often-used stress paradigms, including the Trier Social Stress Test (TSST; Kirschbaum et al., 1993; Schommer et al., 2003; Petrowski et al., 2012). It has been suggested that HPA activity habituates predominantly to psychological stressors such as the TSST (i.e., involving social evaluation, uncontrollability, unpredictability; Dickerson and Kemeny, 2004), and less to physical stressors such as the Cold Pressor Test (Schommer et al., 2003; Grissom and Bhatnagar, 2009). Psychological stressors involve the prefrontal cortex (PFC) that in turn activates the HPA axis via connections with limbic structures, while physical stressors tend to rapidly activate the ANS via reflexive mechanisms in brainstem and hypothalamus (Herman et al., 2003; Ulrich-Lai and Herman, 2009).

In addition to habituation, sensitization effects can emerge due to stress anticipation, i.e. the initiation of stress responses before the actual confrontation with the stressor (Kirschbaum et al., 1995; Preston et al., 2007; Boyle et al., 2016). Evidence for sensitization effects has been found with several widely-used stress paradigms. Such effects appear to depend on the time interval

\footnotetext{
${ }^{1}$ Notably, our definition of response habituation is in line with (Minkley et al. 2014; Boyle et al., 2016), but broader than the one proposed by some authors who distinguish habituation from negative HPA axis feedback processes and associative learning, as mechanisms leading to a decline in HPA reactivity (see Grissom and Bhatnagar, 2009).
} 
between repeated stress inductions, with longer intervals inducing sensitization (Turan et al., 2015).

While the above-mentioned findings derive from studies with either a physical or a psychological stressor, it has been suggested that a stress procedure that combines both physical and psychological elements might be more robust against habituation and sensitization, as it utilizes two pathways rather than just one to stimulate the HPA axis (Minkley et al., 2014; Boyle et al., 2016). Therefore, the present study examined habituation and sensitization to the previously validated Maastricht Acute Stress Test (MAST; Smeets et al., 2012). The MAST combines physical (i.e., hand immersion in ice-cold water) and psychological (i.e. mental arithmetic challenges including psychosocial evaluative threat) elements, and has been shown to be a potent and reliable procedure to elicit subjective, autonomic and glucocorticoid stress responses. The present study is the first to employ this protocol to repeatedly induce a stress response over a three-week and one-month time interval. The focus of the present study is on providing a tool to investigate individual differences in stress responding that are stable over time. Further, sex differences in habituation and sensitization of the stress response were examined.

\section{Methods}

\subsection{Participants}

The present experiment was part of a larger study that included sixty right-handed healthy men $(n=30)$ and women $(n=30)$ undergraduates (mean age $=20.96$ years; $S D=2.82$; range: $18-31$; see Quaedflieg et al., 2016). Participants were screened for eligibility (i.e., psychiatric disorders, smoking, BMI within $18-30 \mathrm{~kg} / \mathrm{m}^{2}$ ). For women, an extra inclusion criterion was the use of oral contraceptives to reduce variability in cortisol responses related to hormonal alterations throughout the menstrual cycle phase (Kudielka et al., 2009). All participants provided written informed consent and were given a minor incentive (course credits or money) in return for their participation. Test protocols were approved by the standing ethics committee of the Faculty of Psychology and Neuroscience, Maastricht University.

\subsection{Procedure and stress induction}

Fig. 1 displays an overview of the procedure of the three test days. All testing took place between 12:30 and 18:00 h to minimize fluctuations in cortisol due to its circadian rhythm (Nicolson, 2008). The laboratory setting, testing procedure, and time of day was kept constant for each participant across all MAST testing sessions. Test days 1 and 2 were separated by three weeks. During this interval, participants returned to the lab six times to measure baseline asymmetry measurement and train frontal alpha asymmetry using EEG neurofeedback. They were not exposed to any stress inducing protocols during these visits. The training was applied in a different room minimizing context effects (Grissom and Bhatnagar, 2009) on the repeated measurements (for details see Quaedflieg et al., 2016). Test day 3 was scheduled exactly one month after test day 2 .

The MAST (Smeets et al., 2012) consists of a 5 min preparation phase in which the task is explained and a 10 min acute stress phase that includes alternating trials of immersing a hand into cold water $\left(2{ }^{\circ} \mathrm{C}\right)$ and counting backwards starting at a random four-digit number along with social-evaluative pressure (i.e., negative feedback and videotaping). Over the three test days, the arithmetic task was altered minimally to reduce predictability. On day 1 , participants counted back in steps of 17 , on day 2 in steps of 13 , and on day 3 in steps of 15 . Neuroendocrine stress responses were measured with synthetic Salivettes (Sarstedt ${ }^{\circledR}$, Etten-Leur, The Netherlands).
On each MAST test session, participants provided saliva samples $20 \mathrm{~min}$ after arrival in the lab ( $\left.t_{\text {baseline }}\right), 5 \mathrm{~min}$ before ( $\left.t_{\text {pre-stress }}\right)$ the MAST and 5 times afterwards $\left(t_{+0}, t_{+10}, t_{+30}, t_{+40}, t_{+55 m i n}\right)$. Samples were stored at $-20^{\circ} \mathrm{C}$ and analyzed with kinetic reaction assay (Salimetrics, Penn State, PA) and luminescence immune assay kit (IBL, Hamburg, Germany) to determine cortisol and sAA values. Subjective stress responses were measured with $100 \mathrm{~mm}$ Visual Analogue Scale (VAS "How stressful was the just performed task for you? “, anchors: not at all - extremely) and the state version of the Positive and Negative Affect Schedule (PANAS; Watson et al., 1988). Higher scores on the NA scale are indicative of higher levels of experienced negative affect. The PANAS was completed at baseline and immediately after each MAST administration.

\subsection{Statistical analysis}

Cortisol and sAA data were log-transformed before analyses as Shapiro-Wilk tests of normality showed typical skewness of the data. Cortisol and SAA responses were analysed using a repeated measures ANOVA with Time ( 7 levels: $t_{\text {baseline }}, t_{\text {pre-stress }}, t_{+0}, t_{+10}$, $\mathrm{t}_{+30}, \mathrm{t}_{+40}, \mathrm{t}_{+55 \mathrm{~min}}$ ) and Day (3 levels: Day 1, Day 2, Day 3) as withinsubject factors and Sex as between-subjects factor. For each test day and each participant individually, the delta increase in SAA and cortisol was computed, defined as peak concentration after the MAST minus pre-stress concentration. The area under the curve with respect to increase (AUCi) was computed per day for both cortisol and sAA representing the total stress response. Moreover, a responder rate was calculated representing participants with a cortisol increase equal to or larger than $1.5 \mathrm{nmol} / \mathrm{l}$ (Miller et al., 2013). Differences in percentage responders between Days and Sex were analysed using Chi-square tests. Two men who did not provide enough saliva, and one with clearly deviant cortisol values (>3SD above the mean baseline and cortisol increase), were excluded from all analyses. From ten participants, sAA values could not be determined. Statistical effects were evaluated using the Greenhouse-Geisser correction and Bonferroni correction when appropriate. $P$-values smaller than 0.05 (two-tailed) were considered statistically significant.

\section{Results}

\subsection{Neuroendocrine stress responses to repeated stress induction}

Mean salivary cortisol concentrations prior to and following repeated administration of the MAST are shown in Fig. 2A. For the entire sample, the Time (7) x Day (3) repeated measures ANOVA revealed the expected significant main effect of Time $\left(F_{(2.26,97.18)}=29.84, p<0.001\right)$ without a significant Time $\mathrm{x}$ Day interaction $\left(F_{(5.03,216,25)}=0.74, p=0.59\right)$ or main effect of Day $\left(F_{(2,86)}=0.87, p=0.42\right)$. Cortisol was stable from $t_{\text {baseline }}$ to $t_{\text {pre-stress }}$ $(p>0.99)$, followed by a significant increase until $t_{40 \mathrm{~min}}$ (for all time points relative to baseline: $p s<0.002$ ), after which cortisol levels returned to baseline (all $p s>0.10$ ). No sex differences were found, with all main effects and 2- and 3-way interactions failing to reach statistical significance (all $F s<1.54$, all $p s>0.18$ ).

For the ANS marker SAA, the time (7) x Day (3) repeated measures ANOVA revealed a significant main effect of Time $\left(F_{(1.54,44.57)}=11.88, p<0.001\right)$ without a significant Time $\mathrm{x}$ Day interaction $\left(F_{(2.77,85.88)}=0.30, p=0.81\right)$ or main effect of Day $\left(F_{(1.62,50,23)}=1.81, p=0.18\right)$. Alpha-amylase was stable from baseline to immediately before stress induction ( $t_{\text {baseline }}-t_{\text {pre-stress; }}$; $p>0.99$ ), increased significantly immediately following stress induction $\left(\mathrm{t}_{\text {pre-stress }}-\mathrm{t}_{+0} ; p=0.04\right)$, then remained stable $\left(\mathrm{t}_{+0}-\mathrm{t}_{+10}\right.$, $\mathrm{t}_{+10}-\mathrm{t}_{+30}, \mathrm{t}_{+30}-\mathrm{t}_{+40} ;$ all $\left.p s>0.90\right)$, and to increase once more from $t_{40}$ to $t_{55}(p=0.02)$. No differences between men and women were 


\section{Test Day (3x)}
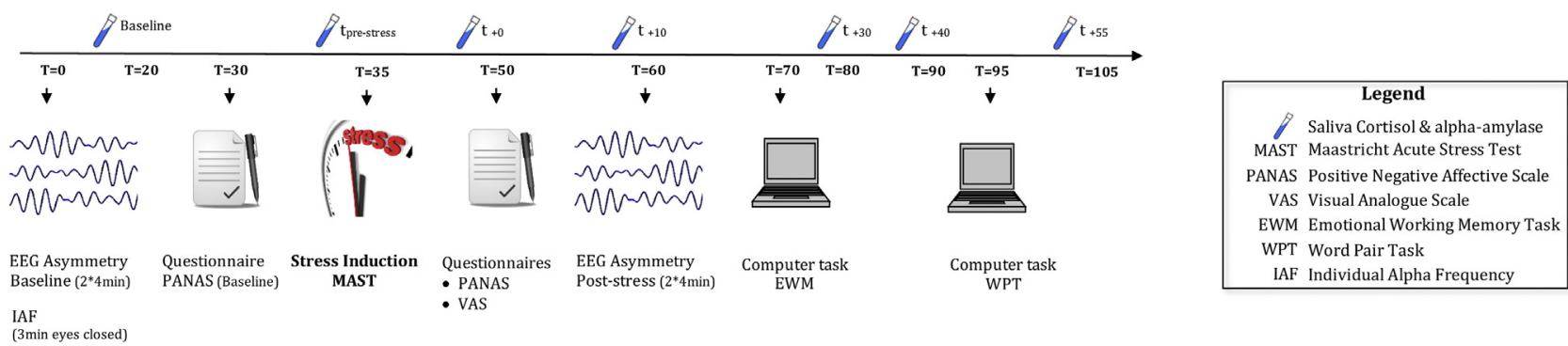

Fig. 1. Overview of the procedure of the test days.
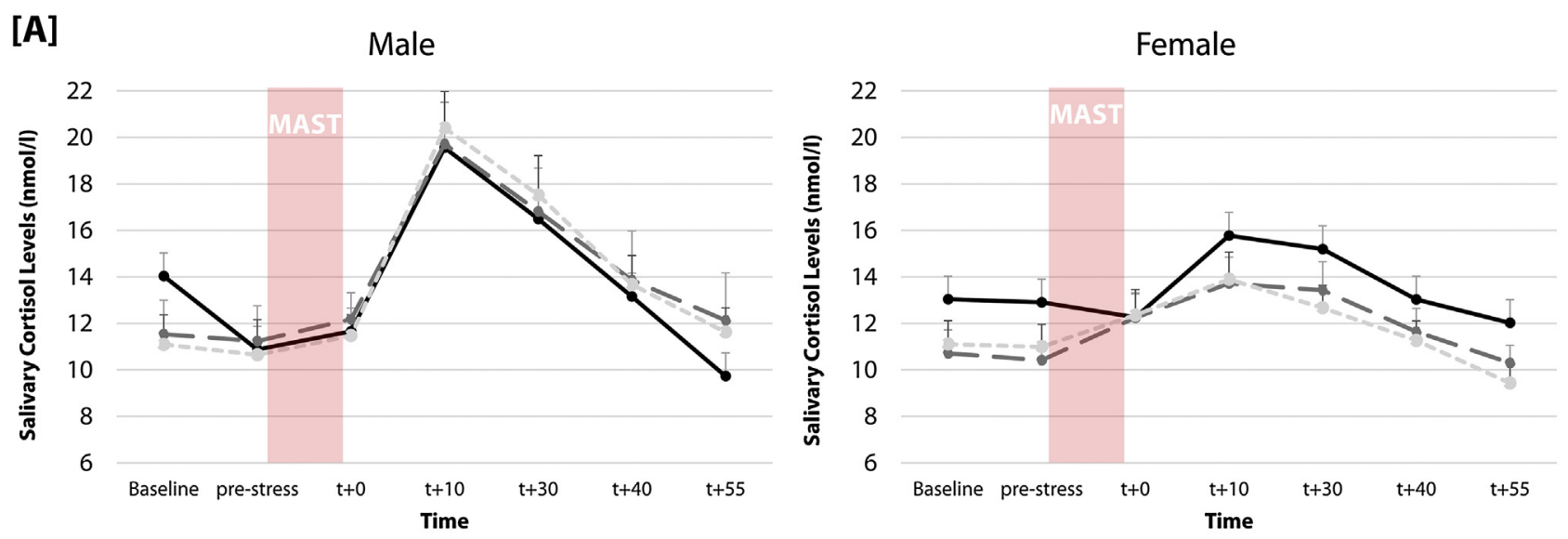

$\rightarrow$ Day $1 \rightarrow$ Day $2 \rightarrow-$ Day 3

[B]

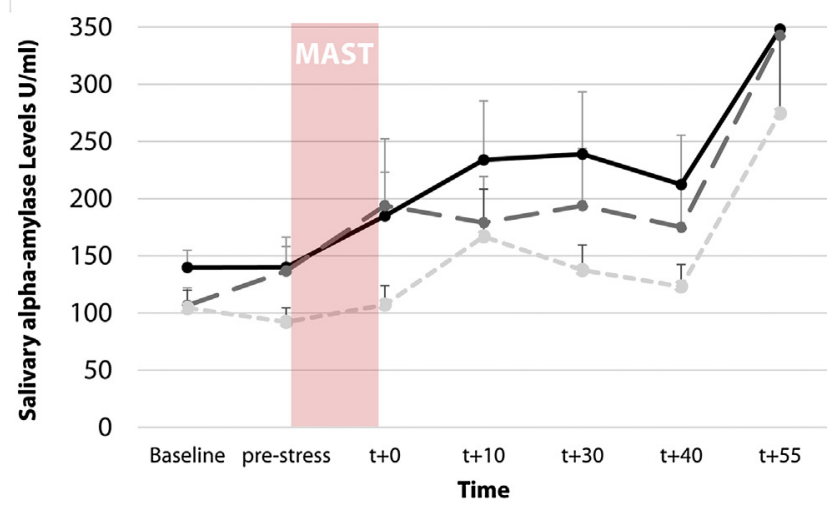

Female

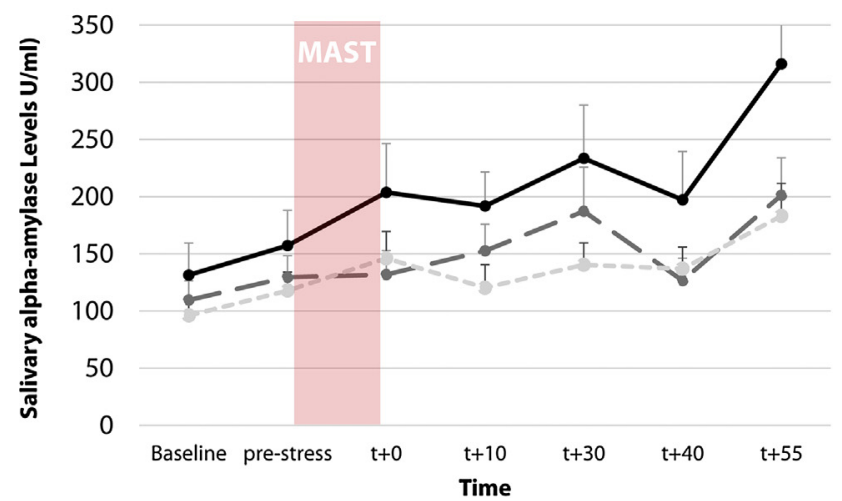

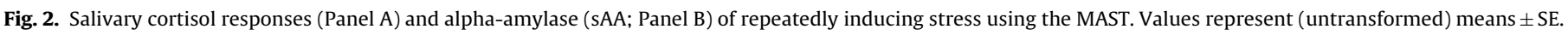

found with all main and 2- and 3-way interactions not reaching statistical significance (all $F s<2.46$, all $p s>0.11$; see Fig. $2 B$ ).

For cortisol and sAA, comparison of the saliva sample at baseline and immediately before the MAST ( $\left.t_{\text {pre-stress }}\right)$ between the three days did not indicate the presence of an anticipation effect (Time (2) x Day (3) interaction Cortisol: $F_{(2,96)}=0.24, p=0.78$; sAA: $\left.F_{(1.62,67.87)}=1.35, p=0.26\right)$.

To assess habituation, repeated measures ANOVAs for the delta increase (max-baseline) in cortisol and SAA and the total stress response (AUCi) were performed. As shown in Fig. 2A, on all three days, an increase in cortisol was seen with no differences due to repeated stress induction (main effect Day: $F_{(1.75,94.39)}=0.58$, $p=0.56$; see Table 1$)$. There was a main effect of $\operatorname{Sex}\left(F_{(1,54)}=8.87\right.$,
Table 1

Means ( \pm SE) of the delta increase (max-baseline) in cortisol for men and women for all three days separately.

\begin{tabular}{lll}
\hline & & $\begin{array}{l}\text { Delta cortisol increase (in } \\
\text { nmol/L) }\end{array}$ \\
\hline Men & Day 1 & $8,45(1,76)$ \\
& Day 2 & $10,40(2,45)$ \\
Day 3 & $10,91(1,61)$ \\
Women & Day 1 & $4,48(1,17)$ \\
& Day 2 & $4,49(0,90)$ \\
& Day 3 & $3,93(0,80)$ \\
\hline
\end{tabular}


Table 2

Associations between the neuroendocrine and subjective stress measures on the three test days.

\begin{tabular}{|c|c|c|}
\hline & Day 2 Cortisol reactivity & Day 3 Cortisol reactivity \\
\hline Day 1 Cortisol reactivity & $r_{58}=0.45, p<0.001$ & $r_{56}=0.57, p<0.001$ \\
\hline \multirow[t]{2}{*}{ Day 2 Cortisol reactivity } & & $r_{56}=0.54, p<0.001$ \\
\hline & Day 2 Cortisol AUCi & Day 3 Cortisol AUCi \\
\hline Day 1 Cortisol AUCi & $r_{57}=0.50, p<0.001$ & $r_{56}=0.50, p<0.001$ \\
\hline \multirow[t]{2}{*}{ Day 2 Cortisol AUCi } & & $r_{55}=0.53, p<0.001$ \\
\hline & Day 2 sAA reactivity & Day 3 sAA reactivity \\
\hline Day 1 sAA reactivity & $r_{50}=0.13, p=0.37$ & $r_{51}=0.43, p<0.002$ \\
\hline \multirow[t]{2}{*}{ Day 2 sAA reactivity } & & $r_{45}=0.12, p=0.43$ \\
\hline & Day 2 sAA AUCi & Day 3 sAA AUCi \\
\hline Day 1 sAA AUCi & $r_{38}=0.29, p=0.08$ & $\mathrm{r}_{37}=0.35, p<0.03$ \\
\hline \multirow[t]{2}{*}{ Day 2 sAA AUCi } & & $r_{45}=-0.06, p=0.74$ \\
\hline & Day 2 VAS Stress & Day 3 VAS Stress \\
\hline Day 1 VAS Stress & $r_{58}=0.19, p=0.16$ & $r_{56}=0.03, p=0.84$ \\
\hline Day 2 VAS Stress & & $r_{56}=0.57, p<0.001$ \\
\hline
\end{tabular}

$p=0.004)$, indicating that the cortisol increase was higher in men, in the absence of a Day x Sex interaction $\left(F_{(1.75,94.39)}=1.14, p=0.32\right)$. The repeated measures ANOVA also demonstrated that the total cortisol response (AUCi) was equal over the three stress induction days $\left(F_{(2,106)}=0.35, p=0.71\right)$. For $\mathrm{sAA}$, the total ANS response increased on all three days (see Fig. $2 \mathrm{~B}$ ) but both the total response and increase from baseline were not different between days (main effect Day; AUCi: $F_{(1.78,76.86)}=0.33, p=0.70$; delta increase: $\left.F_{(1.98,110,84)}=2.67, p=0.07\right)$. For both measures, no sex differences were found (all main and 2-way interactions; all $F \mathrm{~s}<1.35$, all ps $>0.25)^{2}$

Pearson correlations were conducted between stress-related measures obtained on the three test days to evaluate the (test-retest) reliability. As can been seen in Table 2, the correlations between the cortisol reactivity and AUCi measures over the days were significant and positive (all $r \mathrm{~s}>0.45$ ). The correlations between both sAA reactivity and SAA AUCi were smaller and inconsistent, with a significant correlation between day 1 and day 3 $(r=0.35$ ) but not between day 1 and 2 or day 2 and 3 (both $r s<0.29$ ).

Fig. 3 displays the responder rate, representing the percentage of participants with a cortisol increase equal to or larger than 1.5 $\mathrm{nmol} / \mathrm{l}$ that is thought to reflect a cortisol secretory episode (Miller et al., 2013). Ninety-one percent of the sample displayed a significant physiological stress response (i.e., cortisol) to at least one MAST exposure. The percentage of participants who were classified as cortisol responders was $71 \%$ for day $1,72 \%$ for day 2 and $79 \%$ for day 3 . These percentages did not differ significantly between day 1 and $2\left(\chi^{2}(1, N=52)=0.58, p=0.45\right)$, or between day 2 and $3\left(\chi^{2}(1\right.$, $N=51)=0.41, p=0.52$ ). However, they differed between day 1 and 3 $\left(\chi^{2}(1, N=51)=6.07, p=0.01\right)$, with a higher percentage of responders on day 3 . Moreover, $59 \%$ of the sample displayed a significant physiological stress response (i.e., cortisol) on day 1 and day 2, and $57 \%$ with every MAST exposure. On all three days, the percentage of responders did not significantly differ by Sex $\left(\right.$ all $\chi^{2} s<0.40$, all ps>0.53).

\subsection{Subjective stress responses to repeated stress induction}

As shown in Table 3, participants perceived the MAST as distressing, indicated by their ratings of subjective stress and the post-stress increase in NA value of the PANAS. The change in negative affect was significantly different over three days

\footnotetext{
2 The effect of the intervention between test day 1 and 2 on the neuroendocrine stress response was assessed using a test day (2) x intervention (3) repeated measures ANOVA. Intervention group had no effect on the delta increase in cortisol and SAA between test day 1 and 2 (cortisol: test day $\times$ intervention interaction $F_{(2,52)}=1.05, p=0.36$; sAA test day $\times$ intervention interaction $\left.F_{(2,44)}=0.09, p=0.91\right)$. For details, see Quaedflieg et al. (2016).
}

Table 3

Means ( \pm SE) of subjective stress and negative affect (NA) for men and women.

\begin{tabular}{lllll}
\hline \multirow{5}{*}{$\begin{array}{l}\text { Subjective Stress VAS } \\
(\mathbf{0 - 1 0 0})\end{array}$} & PANAS & \\
\cline { 4 - 5 } Men & Day 1 & $67.40(4.56)$ & $13.93(0.95)$ & $18.24(1.07)$ \\
& Day 2 & $71.10(3.28)$ & $13.93(0.72)$ & $15.17(0.73)$ \\
& Day 3 & $69.36(2.05)$ & $13.38(0.81)$ & $14.66(0.76)$ \\
Women & Day 1 & $65.20(4.08)$ & $12.48(0.68)$ & $16.93(1.07)$ \\
& Day 2 & $64.59(3.39)$ & $11.79(0.46)$ & $13.66(1.06)$ \\
& Day 3 & $66.61(2.69)$ & $11.97(0.73)$ & $12.48(0.58)$ \\
\hline
\end{tabular}

$\left(\mathrm{F}_{(2,112)}=16.48, p<0.001\right)$. Follow-up pairwise comparisons indicated that the change in NA on Day 1 was significantly higher than on both day $2(p<0.001)$ and Day $3(p<0.001)$ with no difference between Day 2 and Day $3(p>0.99)$. Comparison of the negative affect at baseline between the three days did not indicate the presence of an anticipation effect (PANAS main effect $\left.F_{(2,112)}=0.54, p=0.58\right)$. Repeated measures ANOVAs demonstrated that there were no differences in VAS subjective stress responses between the three stress inductions $\left(\mathrm{F}_{(1.51,81.77)}=0.44, p=0.59\right)$. For both subjective stress measures, there were no differences between Sex over the three days with all main and 2-way interactions not reaching statistical significance (all $F s<1.26$, all $p s>0.27$ ). ${ }^{3}$

Pearson correlations were conducted between stress related measures obtained on the three test days to evaluate the (test-retest) reliability. As can been seen in Table 2, the correlations between the subjective stress measures were inconsistent, with a significant correlation between day 1 and day $3(r=0.57)$ but not between day 1 and 2 or day 2 and 3 (both $r s<0.19$ ).

\section{Discussion}

The primary aim of the current study was to evaluate the effectiveness of the MAST as a stress induction paradigm that is capable of repeatedly eliciting subjective, autonomic, and HPA axis stress responses. Results demonstrate that the MAST succeeded in generating considerable subjective stress responses, as well as robust increases in sAA and cortisol levels on each of three test days. Meanwhile, there was no indication of anticipation or habituation effect in terms of ANS or HPA axis responses. Moreover, $57 \%$ of the participants displayed a meaningful cortisol increase on all three test days.

\footnotetext{
3 The effect of the intervention between test day 1 and 2 on the subjective stress response was assessed using a test day (2) x intervention (3) repeated measures ANOVA. Intervention group had no effect on the subjective stress response between test day 1 and 2 (PANAS: test day $\times$ intervention interaction $F_{(2,52)}=0.27, p=0.76$ ); VAS: test day $\times$ intervention interaction $\left.F_{(2,52)}=0.55, p=0.58\right)$.
} 


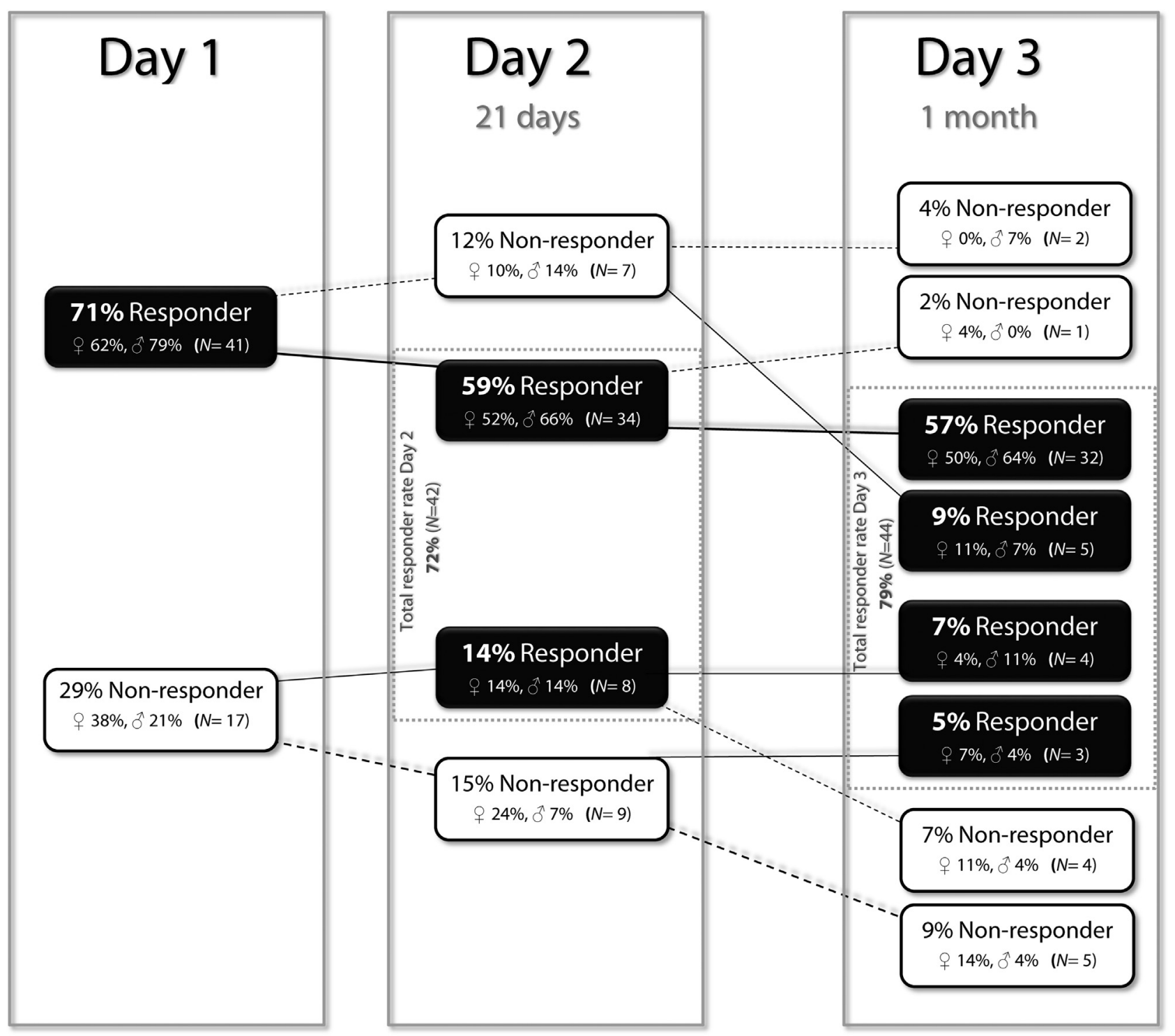

Fig. 3. Responder rate (i.e., $>1.5 \mathrm{nmol} / \mathrm{l}$ ) for all the three stress induction days using the MAST. Note that $57 \%$ of the participants were classified as responders on all three test days.

There were no sex differences in subjective stress, anticipation or habituation over the three days.

Our finding that cortisol responses were robust and regular across testing days is in line with recent studies, using a physical stressor combined with elements of social evaluative feedback that also found no indication of habituation effects (Minkley et al., 2014; Boyle et al., 2016). The development of habituation has been suggested to be mediated by several characteristics of the stressor, including predictability, controllability and stressor intensity (Pitman et al., 1990; Marti et al., 2001; Ulrich-Lai and Herman, 2009). To reduce predictability, the arithmetic task was altered minimally by changing the steps of counting backwards, a procedure we deem essential to help prevent habituation. In addition, animal research has shown that stressor intensity is inversely related to habituation (Pitman et al., 1990). Notably, Smeets et al. (2012) have demonstrated that the MAST is a relatively intense stressor in terms of HPA axis reactivity, compared with other stress protocols such as the cold pressor test. Thus, the intensity of the MAST may make it particularly robust against habituation effects. However, the change in negative affect induced by the MAST decreased after day 1 , while this was not the case for the subjective stress associated with the MAST. A discrepancy between physiological and subjective stress ratings has been reported before and it has been suggested to measure subjective stress multiple times also during stress exposure (Hellhammer and Schubert, 2012).

Anticipation is another phenomenon that has been found with repeated stress exposure (Dickerson and Kemeny, 2004). Anticipation is thought to be initiated by individual appraisal of the demands of a forthcoming challenge. For example, anticipation of a cold ice-water task has been associated with increased ANS activity (Gregg et al., 1999; Boyle et al., 2016). In the current study, we found no evidence for such an anticipation effect neither on physiological (ANS and HPA) nor on subjective (NA) stress. This could be due to the design with repetitive intervention sessions between day 1 and day 2 (see Quaedflieg et al., 2016). This could theoretically have abolished a context-based emotional response before the stressor. However, the test days were performed in a different room than the training sessions, which may decrease the potential effect of context. Moreover, we did not find a sensitization effect between day 2 and day 3, which were performed in the same context and without any intervention session in between. 
With respect to sex, we found no differences in anticipation, habituation, and subjective stress across test days. Much like studies using the TSST or SECPT, we expected and found sex differences in HPA axis reactivity, with larger increases in men compared with women (using hormonal contraceptives) on all three days. It is well known that the efficiency of laboratory stressors to elicit HPA axis responses in women is dependent on changes across the menstrual cycle phases, and that women taking oral contraceptives show significantly smaller salivary cortisol responses than men (e.g. Kirschbaum et al., 1999; for review, see Kudielka et al., 2009). To avoid cortisol response variation related to the women menstrual cycle, women were only included if they used oral contraceptives. Future studies may opt to include women during the various phases of the menstrual cycle, which would provide a unique opportunity to investigate the impact of sex specific hormones on repeated stress induction.

Further attesting the effectiveness of the MAST in repeatedly activating the HPA axis, cortisol responders (displaying cortisol increases larger than $1.5 \mathrm{nmol} / \mathrm{l}$, which is thought to reflect a cortisol secretory episode) were compared between days. In general, the responder rate was high with $71 \%$ for day $1,72 \%$ for day 2 and $79 \%$ for day 3 . Moreover, $59 \%$ of the sample displayed a significant physiological stress response (i.e., increases larger than $1.5 \mathrm{nmol} / \mathrm{l}$ cortisol) on day 1 and day 2, and 57\% with every MAST exposure. Furthermore, individual cortisol response patterns seemed to be relatively stable, as shown by the robust correlations across the three days. However, for both the ANS and subjective stress measures, the correlations were small and inconsistent, suggesting a larger state influence on these measures. These findings indicate intra-individual differences that future studies could unravel by including additional measures (e.g., personality traits).

With respect to the autonomic stress response, we found that sAA increased significantly between $t_{40}$ and $t_{55}$ on all three test days. Participants performed a working memory task with emotional pictures in-between these two samples. Emotional pictures have been used in previous studies to induce an autonomic stress response (Sinha et al., 2004; Yang et al., 2007), potentially explaining the observed increase in sAA. In line with the established way to analyze the HPA axis stress response, we also calculated the delta increase and AUCi for the autonomic stress response sAA. In comparison to cortisol, where an increase equal to or larger than 1.5 nmol/l is known to reflect a cortisol secretory episode (Miller et al., 2013), the interpretation of the delta increase in sAA is far less straightforward.

Some limitations to the current study are worth mentioning. First, the data are part of a larger study investigating the efficacy of a neurofeedback intervention. This intervention was applied between day 1 and day 2 and consisted of three different interventions including a placebo condition, that may have influenced the results. However, we could demonstrate that the different interventions between day 1 and day 2 did not influence the stress responding. Second, animal studies have shown that the frequency and timing of stress can alter HPA reactivity, with more pronounced habituation effects when the intervals between stimulations are shorter (Grissom and Bhatnagar, 2009). To further investigate the usefulness of the MAST as a tool to repeatedly induce stress and for future research aimed at investigating the efficacy of interventions for increasing stress resiliency, a shorter time interval between repeated stressing is needed.

In sum, the current study demonstrates the value of the MAST as a concise stress paradigm capable of repeatedly eliciting subjective, autonomic and glucocorticoid stress responses. The MAST presents a valuable opportunity for researchers interested in repeatedly eliciting stress responses so as to, for example, investigate interven- tions that target stress reactivity or for further exploring individual differences in stress vulnerability.

\section{References}

Boyle, N.B., Lawton, C., Arkbage, K., West, S.G., Thorell, L., Hofman, D., Weeks, A., Myrissa, K., Croden, F., Dye, L., 2016. Stress responses to repeated exposure to a combined physical and social evaluative laboratory stressor in young healthy males. Psychoneuroendocrinology 63, 119-127, http://dx.doi.org/10.1016/j. psyneuen.2015.09.025.

de Kloet, E.R., Joels, M., Holsboer, F., 2005. Stress and the brain: from adaptation to disease. Nat. Rev. Neurosci. 6, 463-475, http://dx.doi.org/10.1038/nrn1683.

Dickerson, S.S., Kemeny, M.E., 2004. Acute stressors and cortisol responses: a theoretical integration and synthesis of laboratory research. Psychol. Bull. 130, 355-391, http://dx.doi.org/10.1037/0033-2909.130.3.355.

Gregg, M.E., James, J.E., Matyas, T.A., Thorsteinsson, E.B., 1999. Hemodynamic profile of stress-induced anticipation and recovery. Int. J. Psychophysiol. 34, 147-162.

Grissom, N., Bhatnagar, S., 2009. Habituation to repeated stress: get used to it. Neurobiol. Learn Mem. 92, 215-224, http://dx.doi.org/10.1016/j.nlm.2008.07. 001.

Hellhammer, J., Schubert, M., 2012. The physiological response to Trier Social Stress Test relates to subjective measures of stress during but not before or after the test. Psychoneuroendocrinology 37, 119-124, http://dx.doi.org/10. 1016/j.psyneuen.2011.05.012.

Herman, J.P., Figueiredo, H., Mueller, N.K., Ulrich-Lai, Y., Ostrander, M.M., Choi, D.C. Cullinan, W.E., 2003. Central mechanisms of stress integration: hierarchical circuitry controlling hypothalamo-pituitary-adrenocortical responsiveness. Front. Neuroendocrinol. 24, 151-180.

Kirschbaum, C., Pirke, K.M., Hellhammer, D.H., 1993. The 'Trier Social Stress Test'?a tool for investigating psychobiological stress responses in a laboratory setting. Neuropsychobiology 28, 76-81, 119004

Kirschbaum, C., Prussner, J.C., Stone, A.A., Federenko, I., Gaab, J., Lintz, D. Schommer, N., Hellhammer, D.H., 1995. Persistent high cortisol responses to repeated psychological stress in a subpopulation of healthy men. Psychosom. Med. 57, 468-474.

Kirschbaum, C., Kudielka, B.M., Gaab, J., Schommer, N.C., Hellhammer, D.H., 1999. Impact of gender, menstrual cycle phase, and oral contraceptives on the activity of the hypothalamus-pituitary-adrenal axis. Psychosom. Med. 61, 154-162.

Kudielka, B.M., Hellhammer, D.H., Wust, S., 2009. Why do we respond so differently? Reviewing determinants of human salivary cortisol responses to challenge. Psychoneuroendocrinology 34, 2-18, http://dx.doi.org/10.1016/j. psyneuen.2008.10.004.

Marti, O., Garcia, A., Valles, A., Harbuz, M.S., Armario, A., 2001. Evidence that a single exposure to aversive stimuli triggers long-lasting effects in the hypothalamus-pituitary-adrenal axis that consolidate with time. Eur. J. Neurosci. 13, 129-136.

Miller, R., Plessow, F., Kirschbaum, C., Stalder, T., 2013. Classification criteria for distinguishing cortisol responders from nonresponders to psychosocial stress: evaluation of salivary cortisol pulse detection in panel designs. Psychosom. Med. 75, 832-840, http://dx.doi.org/10.1097/PSY.0000000000000002.

Minkley, N., Schroder, T.P., Wolf, O.T., Kirchner, W.H., 2014. The socially evaluated cold-pressor test (SECPT) for groups: effects of repeated administration of a combined physiological and psychological stressor. Psychoneuroendocrinology 45, 119-127, http://dx.doi.org/10.1016/j.psyneuen.2014.03.022.

Nicolson, N.A., 2008. Measurement of cortisol. In: Luecken, L.J., Gallo, L.C. (Eds.), Handbook of Physiological Research Methods in Health Psychology. Sage, Los Angeles, pp. 37-74.

Petrowski, K., Wintermann, G.B., Siepmann, M., 2012. Cortisol response to repeated psychosocial stress. Appl. Psychophysiol. Biofeedback 37, 103-107, http://dx. doi.org/10.1007/s10484-012-9183-4.

Pitman, D.L., Ottenweller, J.E., Natelson, B.H., 1990. Effect of stressor intensity on habituation and sensitization of glucocorticoid responses in rats. Behav. Neurosci. 104, 28-36.

Preston, S.D., Buchanan, T.W., Stansfield, R.B., Bechara, A., 2007. Effects of anticipatory stress on decision making in a gambling task. Behav. Neurosci. 121, 257-263, http://dx.doi.org/10.1037/0735-7044.121.2.257.

Quaedflieg, C.W.E.M., Smulders, F.T., Meyer, T., Peeters, F., Merckelbach, H., Smeets, T., 2016. The validity of individual frontal alpha asymmetry EEG neurofeedback. Soc. Cogn. Affect. Neurosci. 11, 33-43, http://dx.doi.org/10. 1093/scan/nsv090.

Schommer, N.C., Hellhammer, D.H., Kirschbaum, C., 2003. Dissociation between reactivity of the hypothalamus-pituitary-adrenal axis and the sympathetic-adrenal-medullary system to repeated psychosocial stress. Psychosom. Med. 65, 450-460.

Sinha, R., Lacadie, C., Skudlarski, P., Wexler, B.E., 2004. Neural circuits underlying emotional distress in humans. Biobehavioral Stress Response: Protective and Damaging Effects 1032, 254-257, http://dx.doi.org/10.1196/annals.1314.032.

Smeets, T., Cornelisse, S., Quaedflieg, C.W.E.M., Meyer, T., Jelicic, M., Merckelbach, H., 2012. Introducing the Maastricht Acute Stress Test (MAST): a quick and non-invasive approach to elicit robust autonomic and glucocorticoid stress responses. Psychoneuroendocrinology 37, 1998-2008, http://dx.doi.org/10. 1016/j.psyneuen.2012.04.012. 
Turan, B., Foltz, C., Cavanagh, J.F., Wallace, B.A., Cullen, M., Rosenberg, E.L., Jennings, P.A., Ekman, P., Kemeny, M.E., 2015. Anticipatory sensitization to repeated stressors: the role of initial cortisol reactivity and meditation/emotion skills training. Psychoneuroendocrinology 52, 229-238, http://dx.doi.org/10.1016/j.psyneuen.2014.11.014.

Ulrich-Lai, Y.M., Herman, J.P., 2009. Neural regulation of endocrine and autonomic stress responses. Nat. Rev. Neurosci. 10, 397-409, http://dx.doi.org/10.1038/ nrn2647.

Watson, D., Clark, L.A., Tellegen, A., 1988. Development and validation of brief measures of positive and negative affect: the PANAS scales. J. Pers. Soc. Psychol. 54, 1063-1070.
Wingenfeld, K., Wolf, O.T., 2015. Effects of cortisol on cognition in major depressive disorder, posttraumatic stress disorder and borderline personality disorder - 2014 Curt Richter Award Winner. Psychoneuroendocrinology 51, 282-295, http://dx.doi.org/10.1016/j.psyneuen.2014.10.009.

Yang, H.Y., Zhou, Z.Y., Liu, Y., Ruan, Z.C., Gong, H., Luo, Q.M., Lu, Z.H., 2007. Gender difference in hemodynamic responses of prefrontal area to emotional stress by near-infrared spectroscopy. Behav. Brain Res. 178, 172-176, http://dx.doi.org/ 10.1016/j.bbr.2006.11.039. 